\title{
Liquidity and the Impact of Information Shocks: A Macroeconomics Course Application
}

The relationship between the macroeconomy and equity share prices is of critical importance. So if that is true, then how does the economy affect equity prices and vice versa? In many cases, it is news about the macroeconomy and, more precisely, unexpected news. ${ }^{1}$ The release of "surprises" about the economy is referred to as "information shocks" which can have swift and significant effects on stock prices. Information shocks are fundamentally different than the "liquidity shocks" described earlier in the Finance chapter. In the case of liquidity shocks, we saw how the structure of the financial market itself and the quantity and quality of orders submitted can affect the ability of investors to find the "true" price of a stock through a process referred to as "price discovery." In our case here, information shocks also have a large impact on the price discovery process, but the main driver of these shocks is the advent of unexpected news, not the lack of liquidity within a financial market. In this chapter, we describe some examples of macroeconomic-related shocks and their effects on the US stock market, as well as the inter-relationships between financial markets and the economy.

Given the enormous size and complexity of a nation's economy, information related to the macroeconomy covers a wide array of items. What factors are most important? First and foremost are interest rates that apply to individual firms, specific industries, as well as broader sectors of the economy. In macroeconomics, the relationship primarily focuses on the interactions between interest rates, the private sector (comprised of consumers, investors, and businesses), and government policymakers at the Federal Reserve (via monetary policy) and the US Treasury (via fiscal policy). Because interest rates represent the rental price of money, they serve as the

\footnotetext{
${ }^{1}$ As discussed in the Finance chapter, financial markets can be "informationally efficient" if they process and incorporate unexpected news quickly and correctly into current stock prices. According to the "efficient market hypothesis" (EMH), if markets properly and rapidly impound new information into stock prices, then the behavior of these prices should resemble a "random walk" and thus lead to unpredictable price movements over time. As noted in the Finance chapter, financial markets are reasonably efficient but not always perfect and thus can present opportunities for alert investors and traders to spot price trends before others uncover them.
} 
main link between the "real world" of the macroeconomy and the "financial world" of equity and bond markets. Both the private sector and the government watch interest rates closely as a signal of the economy's current and future condition in order to make better decisions in allocating scarce resources to their most efficient uses. Through the liquidity provided by financial markets, investors can channel their savings to profitable investments which ultimately leads to stronger economic growth for society. Thus, economists and investors should consider the liquidity of financial markets to better understand how the financial and real worlds interact with each other.

\subsection{Economic Conditions, Business Cycles, and the Role of Interest Rates}

The key driver of business cycle fluctuations in most countries is business investment, and sudden changes in this investment can lead to economic booms as well as recessions. Business executives are therefore constantly assessing the economic landscape to see what consumers are buying (and in what quantities), as well as tracking consumers' confidence in order to decide how much to invest in the future. As consumer demand rises and falls, businesses react quickly by adjusting the amount of investment in plant, equipment, inventories, research, and new technology. These adjustments can lead to sharp changes in employment and wages which ultimately affect further changes in consumers' spending patterns. The relationship between investment and consumption is circular, and this leads to the cyclical nature of most economies, as booms are followed by recessions which eventually lead to recoveries and then further economic booms.

Interest rates are also greatly affected by business investment because firms typically borrow money from lenders and investors in order to finance future expansion. This increased demand for money places upward pressure on interest rates unless a government's central bank such as the U.S. Federal Reserve (commonly referred to as "the Fed") increases the supply of money.

The interaction between investment and interest rates is complex because the effects can be simultaneous in nature. That is, business investment not only affects interest rates, but the level of these rates, in turn, affects the level of investment. For example, if consumers suddenly buy more goods and services, businesses will invest more and ultimately push interest rates up due to an increased demand for money. However, if interest rates rise too high, then businesses will cut back on investment because the cost of financing the new plant and equipment or inventory can now exceed the profit that businesses could earn on this new investment. Eventually, the reduction in investment due to higher interest rates will lead to a lower demand for money. This will then result in lower rates in the future, thus creating a classic cycle between investment and interest rates.

Changes in business investment are, therefore, watched closely by policymakers such as those at the Federal Reserve. The Fed will try to stimulate and stabilize the economy by adjusting the Federal Funds rate in order to maintain steady growth 
with low inflation. ${ }^{2}$ To adjust this key interest rate upward (or downward), the Fed typically uses open market operations ("OMO") to sell (or buy) U.S. Treasury securities in the government bond markets where the primary trading partners are financial institutions such as commercial banks and securities broker-dealers. When the Fed sells U.S. Treasurys via OMO activity, the goal is to reduce the supply of money and increase the Federal Funds rate (assuming the demand for money remains relatively constant). By selling U.S. Treasurys, the Fed is withdrawing dollars from the economy and reducing the money supply because investors have to give up their cash to acquire these government securities. Economists call this a "contractionary" monetary policy because the goal of raising this key rate is to cause banks and other lenders to increase their loan rates and, in so doing, make it more costly for businesses and consumers to afford additional investment and consumption. This can eventually lead to a contraction of the economy by reducing business investment because higher interest rates can "cool off" an economy that might be on the verge of "overheating" through increased price inflation. In contrast, an "expansionary" monetary policy occurs when the Fed buys U.S. Treasurys to inject more money into the economy in order to lower the Federal Funds rate and stimulate greater investment by businesses and consumers.

\subsection{The Federal Reserve and the Link Between the Macroeconomy and Financial Markets}

The Fed's OMO actions create a constant "interactive feedback loop" between the macroeconomy and financial markets. As macroeconomic conditions and interest rates change, both the Fed and market participants such as banks, brokers, and asset managers adjust their holdings of not only U.S. Treasury securities but also riskier assets such as corporate bonds and equity shares. Investors in financial markets respond to unexpected news about the economy and interest rates because a stock's or bond's value is determined by the present value of its expected future cash flows. As noted in the Microeconomics chapter, this investor reaction is driven by changes in the risk-free rate that can affect the Capital Market Line according to the Capital Asset Pricing Model (CAPM). In that model, as the risk-free rate goes up, the intercept rises, the slope falls, and tangency with the efficient frontier moves up and to the right, thus raising investors' required returns for the market portfolio. The Capital Market Line concept helps explain how the Fed's actions and policy statements can create information shocks that lead to a large amount of trading activity in all types of securities which, in turn, depend on the liquidity of the financial markets. Through this daily trading of literally trillions of dollars' worth of securities, the financial markets serve an important purpose as the primary mechanism for discovering the proper prices of financial assets. As noted earlier in the Finance and Microeconomics chapters, price discovery is a major function of any well-operating financial market.

\footnotetext{
${ }^{2}$ The Federal Funds rate is the interest rate commercial banks charge each other for overnight borrowings to meet short-term liquidity needs.
} 
A good example of this interactive feedback loop can be seen in the Fed's October 2018 announcement of their plans to continue raising interest rates and in how this contractionary policy jolted the U.S. stock markets and caused a sharp price decline by the end of December 2018. In response to this negative market reaction, the chairman of the Fed, Jerome Powell, stated in early January 2019 that the Fed's contractionary stance would be put on "pause." The financial markets viewed this as good news because it was feared that continued hikes in the Federal Funds rate could cause the U.S. economy to fall into a recession. The U.S. stock market reacted very positively to this change in monetary policy during the first quarter of 2019. Seeing this, the Fed ultimately decided to cut interest rates three times and led to a 29\% increase in the S\&P 500 during 2019. More details about this example of interactions between the economy and financial markets are discussed later in this chapter.

\subsection{The Impact of Information Shocks on Divergent Expectations and Price Discovery}

Changes in Fed policy can affect the liquidity of financial markets not only directly by the Fed's OMO activity but also through the information "signals" contained within these policy changes. For example, an unexpected cut in the Federal Funds rate is an information shock that might signal to investors and business executives that the economy is currently weak but, at the same time, lets everyone know that the Fed is acting to stimulate economic conditions and thus will strengthen the macroeconomy in the future. This can create "divergent expectations" (a concept discussed in the Finance chapter) where some relatively pessimistic market participants will trade based on the short-term economic weakness (e.g., by buying bonds which rise in value, causing interest rates to fall, and also by selling stocks). In contrast, more optimistic market participants will focus on the positive prospects of expected future, longer-term economic strength and choose to invest in riskier assets that will perform well in an expanding economy (e.g., by selling bonds and buying stocks).

In financial markets jargon, the pessimistic traders are typically called "bears," while the optimistic traders are described as "bulls." Trading in financial markets between these two types of investors will then help discover the proper "equilibrium" prices of stocks and bonds. These prices are informative signals. However, it might take not only an entire trading day but also several days (or even weeks) for the bulls and bears to trade with each other until a new equilibrium price is discovered. This protracted price discovery process occurs because economic reports released after the initial information shock can sometimes be conflicting in nature. For example, bullish economic data released one day can be followed by bearish data the next day, thus sowing confusion as to what the true impact of these reports will be on a stock's price.

To illustrate the important role of price discovery, a simplified example can be used based on the stock price of a hypothetical firm, ABC. Prior academic research by Handa, Schwartz, and Tiwari (2003) suggests that we can describe the 
divergence of investor expectations by dividing a set of participants into two groups. Let us call one group the bulls and the other the bears. We can assume the bulls value $\mathrm{ABC}$ shares at $\$ 30$ and the bears value $\mathrm{ABC}$ shares at $\$ 20$. The bulls are the buyers, and the bears are the sellers due to their divergence in expectations about the future value of the stock based on some unexpected macroeconomic news such as a sudden change in the Federal Reserve's monetary policy. Let participants arrive sequentially in the financial market and either (1) post orders to buy or to sell or (2) trade immediately at bid or offer prices set by orders that have previously been placed.

Equilibrium bid and offer prices for $\mathrm{ABC}$ stock can be determined if one further piece of information is known - the percentage of participants who are bulls (denoted by $k$ ) and the percentage of participants who are bears (denoted by $1-k$ ). In this simplified setting, the divergence of expectations among participants has two dimensions: (1) the magnitude of the difference between the high and the low valuations (in our case, $\$ 30-\$ 20$ ) and (2) the distribution of investors between the two valuations (as represented by $k$ ). The value of ABC's stock will therefore fall somewhere between $\$ 20$ and $\$ 30$ depending on the value of $k$. For example, if half of all traders are bullish $(k=.50)$, then the equilibrium price should be $\$ 25$ (i.e., $.50 \times \$ 30$ plus $.50 \times \$ 20=\$ 25)$.

How do participants know or find out about the value of $k$ ? The primary way is by observing the orders that are sent to the financial market. These orders are created in response to news about ABC's prospects as well as overall macroeconomic conditions. Thus, participants discover the value of $k$ through the orders that are revealed as trading progresses. As these trades are reported for everyone to see, the price of $\mathrm{ABC}$ shares fluctuates in response to changing beliefs about $k$.

In actual markets, participants' divergent expectations are distributed over a wider range of valuations, and we cannot refer simply to one variable, $k$. Nevertheless, the conclusion still holds - when expectations are divergent, prices must be discovered through the trading process in financial markets. The process is not simple and can be messy and protracted at times as investors sort through a multitude of signals from both the financial markets and the macroeconomy, many of which might be conflicting.

\subsection{The Various Types of Financial Markets}

As discussed in the limit order book example of the Finance chapter, a thin, illiquid financial market imposes higher transaction costs on investors and can deter some participants from placing orders in the first place. For example, in an illiquid limit order book market (also referred to as a continuous "order-driven" market), an information shock can cause a sudden surge in orders to buy or sell, and this might result in a wider bid-ask spread. If no new bids and offers enter the limit order book, then the bid-ask spread that investors must pay will be much higher, and thus, it will become more expensive to trade a company's stock. In addition, this higher spread can lead to greater price volatility because even if the best bid and ask quotes remain constant, transaction prices will bounce between the bid and offer due to the 
intermittent arrival of market orders to sell against the lower bid and market orders to buy against the much higher offer. This effect is commonly referred to as the "bid-ask bounce," and this bounce contributes to short-term price volatility.

Stock prices also become more volatile in a thin order book due to "market impact," which occurs when a large buy order pushes the execution price above the best offer or a large sell order pushes the price below the best bid. When market impact is sizable, price volatility is increased because prices will then typically revert to levels observed just before the large market order was placed. Price discovery could also be more difficult in a thin market, and if so, this too would contribute to price volatility.

Consequently, a thin order book can make price discovery more difficult which, in turn, leads to less informative signals about how investors are reacting to news regarding the macroeconomy and the financial health of a specific stock such as ABC. Thus, the signals from an illiquid financial market are "noisier" than those generated by a deep, liquid market. In the extreme case, a very illiquid financial market that is buffeted by frequent information shocks leads to unreliable signals from investors, and the interactive feedback loop between the macroeconomy and financial market becomes broken. This outcome is a negative one for all parties because investors, business executives, and policymakers no longer have freely flowing information about how their actions are affecting both the macroeconomy and financial markets. Consequently, illiquidity can stymie economic growth and undermine the returns offered by stocks and bonds.

Beyond the limit order book, or continuous order-driven, market structure described in the Finance chapter, there are two other primary ways to organize a financial market: (1) a periodic call auction and (2) a dealer market (also known as a "quote-driven" market). A call auction is a periodic (as opposed to a continuous) order-driven market. These alternative market structures can help large buyers and sellers that might otherwise be reluctant to enter their orders into a quote-driven continuous market. These traders are reluctant to submit large orders because of the fear of unduly pushing prices up or down (known as market impact). Another concern for these large buyers/sellers is that other traders might find out about their orders and it might lead to trades at unfavorable prices (usually referred to as "information leakage"). Unrevealed orders are referred to as "latent liquidity."

As discussed in the Finance chapter, with a call auction, participant's orders are batched together for simultaneous execution at a single clearing price at a preannounced point in time. When the market is called, all buy orders equal to and greater than the clearing price are executable, as are all sell orders equal to or less than the clearing price. Trading prices are set at values that maximize the number of shares that execute. By batching many transactions together, a call auction concentrates liquidity and, in so doing, can significantly decrease transaction costs for participants. Calls also facilitate "quantity discovery" by allowing larger orders to be executed with less market impact and reduced information leakage. The integration of revealed and latent liquidity could be better harmonized in a call auction as the latent liquidity provider would be more comfortable with revealing the orders. 
Why? For one reason: he/she can get price improvement, whereas, with exceptions, this does not happen with continuous order-driven trading.

In contrast to a call auction, in a dealer market, dealers (also called "market makers") state the prices at which public customers can buy or sell shares. A dealer posts two-sided quotes: a bid quote at which the market maker will buy shares if a customer is looking to sell and an ask quote at which the market maker will sell shares if a customer is looking to buy. As noted earlier, a dealer market is commonly referred to as a quote-driven market. The primary benefit of a dealer market is that it can provide immediacy by allowing public buyers and sellers to interact directly and quickly with a dealer so that these public customers face less risk of not having their orders executed (referred to as "execution risk"). Thus, a dealer market can reduce execution risk, but this usually comes with a trade-off in terms of wider bidask spreads and less transparency about other buyers and sellers in the market.

In addition to order-driven continuous markets, quote-driven markets, and periodic call auctions, other mechanisms exist to meet more specialized trading needs. For example, a block trading mechanism is used to handle the sizable orders of large investors (typically institutional) who are trying to limit the adverse impact of their large orders on the prices they wind up trading at. A large order, typically defined as an order for 10,000 shares or more, can be negotiated either person to person (face to face or via telephone or instant message) or executed via an electronic interface.

As new technology has emerged, financial markets and investor trading strategies continue to evolve. For example, relatively new trading mechanisms that allow orders to trade without publicly disclosing their trading interests are called "dark pools." Dark pools are private trading forums as opposed to trading that takes place on public exchanges like the New York Stock Exchange and Nasdaq. These mechanisms are so named to emphasize their lack of transparency compared to "lit" public exchanges. While dark pools came about primarily to facilitate block trading by institutional investors, they are now used for trading of both small- and large-sized orders. Small retail orders received by large brokerage houses can be executed internally, without being sent to public exchanges, and this too is considered a form of dark pool trading.

Dark pools are so-called dark to distinguish them from "lit" markets. Public stock exchanges are considered lit because of their higher levels of order book transparency. The following applies: (1) price discovery typically takes place through trading in public exchanges; (2) these prices are then used for trading in the dark pools; and (3) dark pools enhance quantity discovery, particularly for the large participants who, otherwise, are reluctant to send their orders to lit markets. The growing separation of price discovery and quantity discovery is not, however, without drawbacks. Efficient values for price and quantity are better attained when the two variables are determined simultaneously. Interestingly, the two are determined simultaneously in call auction trading.

Given the competing market structure models described above, you might ask: which one is the best one to use for trading? As in many things, the answer is "it depends" on what a customer needs. Since different types of traders (e.g., retail versus institutional) have different needs, it is not surprising that exchanges and 
other trading venues now offer multiple market structure models in a "hybrid" format. For example, major international stock exchanges typically open and close trading with a call auction, and some have intraday auctions. Batching orders in a multilateral call auction trading system facilitates order handling, sharpens price discovery, and enhances market transparency. Call auctions do not provide immediacy, but trading in the continuous market does. The immediacy offered by a continuous market that directly follows an opening call is immensely appealing to market participants. Hence, a hybrid market structure that combines continuous trading and call auctions offers significant advantages. Furthermore, when under severe stress, price discovery breaks down in the continuous market, trading is halted, and the market is re-opened with a call auction.

Regardless of the specific structure of a financial market, the Fed and other observers of the economy need to pay attention to the liquidity of these financial markets. Investors in these trading venues not only react to signals from the Fed but also produce their own signals of investors' views of the macroeconomy via their trading patterns. Thus, price fluctuations in the bond and stock markets are used by the Fed and the U.S. Treasury to see if their expansionary and contractionary actions are having the proper effect on the economy and to assess investor reactions to the policies they announce. This simultaneous relationship between the actions of investors, business executives, and policymakers creates a tightly linked system that can allocate scarce economic resources more efficiently to create a well-functioning and productive macroeconomy. As noted earlier, this linkage between the "real world" and the "financial world" depends crucially on the liquidity of financial markets, as provided by the various market structures we have just presented.

\subsection{Example of an Information Shock Based on the Fed's Actions and the Financial Market's Reactions}

To illustrate some economic-related information shocks and the interplay between the economy and financial markets, we can examine how the Fed's statements by Chairman Jerome Powell in early October 2018 about possible further Federal Funds rate hikes caused a sharp drop in equities during the fourth quarter of 2018. The S\&P 500 stock market index fell 14.0\% between the end of September 2019 and the end of December 2019. The swift and sharp negative reaction by the stock and bond markets to Powell's unexpected statement that there is "a long way to go" before further rate increases would stop prompted the Fed chairman to declare in early January 2019 that the Fed will instead show "patience" in terms of any further rate increases. The stock market immediately rallied $+3.4 \%$ on the day of Powell's comments about a slower approach to Federal Funds rate increases. The Fed held rates steady for most of 2019 and then actually started lowering interest rates during August-November 2019. Three successive 0.25\% cuts to the Federal Funds rate decreased it from a range of $2.0-2.5 \%$ in the summer of 2019 to $1.50-1.75 \%$ by November 2019. The Fed referred to this change from contractionary to expansionary monetary policy as a "mid-cycle adjustment" given concerns about a possible 


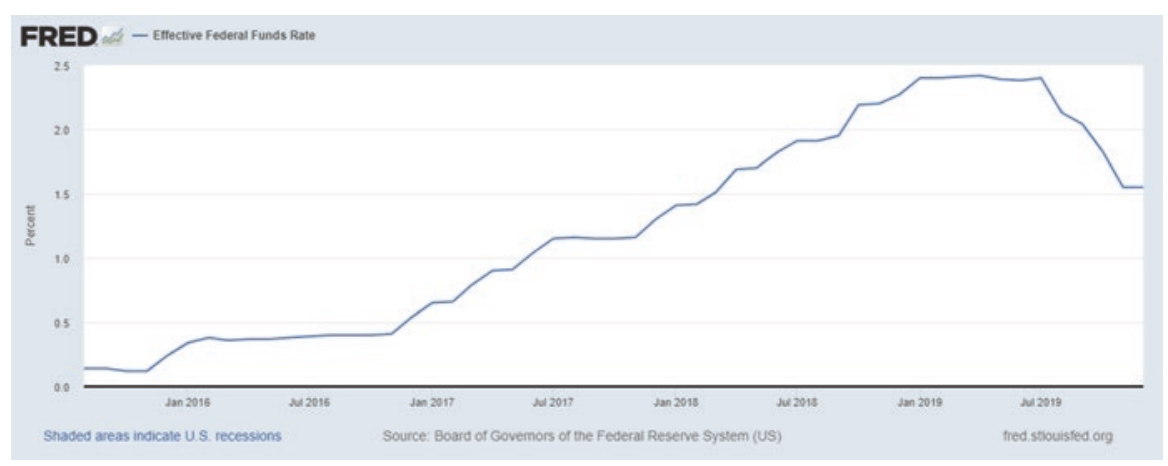

Exhibit 3.1 Federal funds rate history (2015-2019)

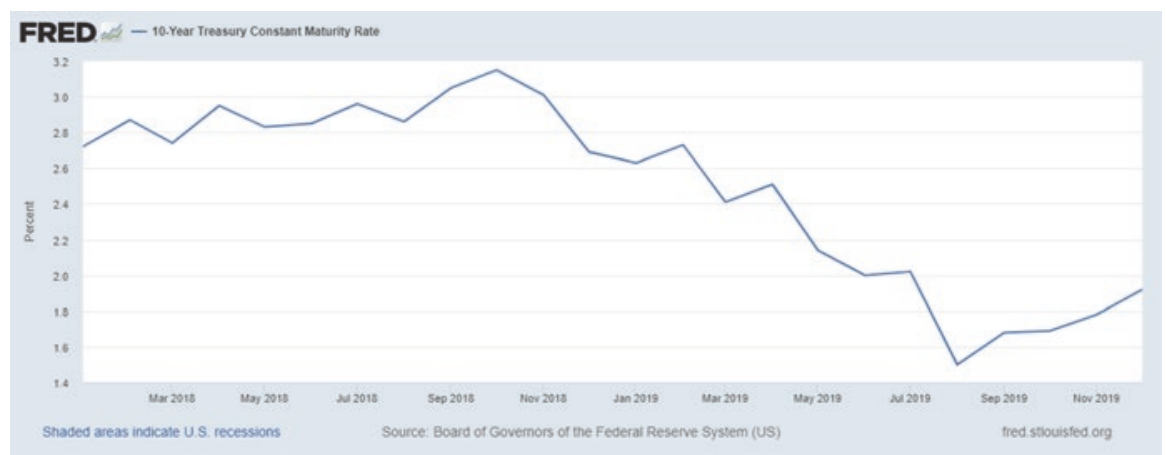

Exhibit 3.2 Ten-year US Treasury note yields (2018-2019)

economic slowdown. The Fed's statements in January, followed by the rate cuts later in the year, helped fuel a quick and vigorous rebound in equities during 2019, with the S\&P 500 stock index rising $29 \%$ over the course of the year from 2,506.85 to 3230.78 .

The sequence of events described above represents a clear example of the continuous feedback loop between the macroeconomy and financial markets. Presented below are some graphs and news items related to the events that unfolded during October 2018-December 2019.

The unexpected news first revealed by Fed Chairman Powell's statement in early October 2018 was quoted by CNBC.com as follows: "We [i.e., the Fed] may go neutral, but we're a long way from neutral at this point, probably." This statement was made after the Fed had already raised the Federal Funds rate nine times, starting in December 2015. Powell's statement was a surprise because many analysts and 


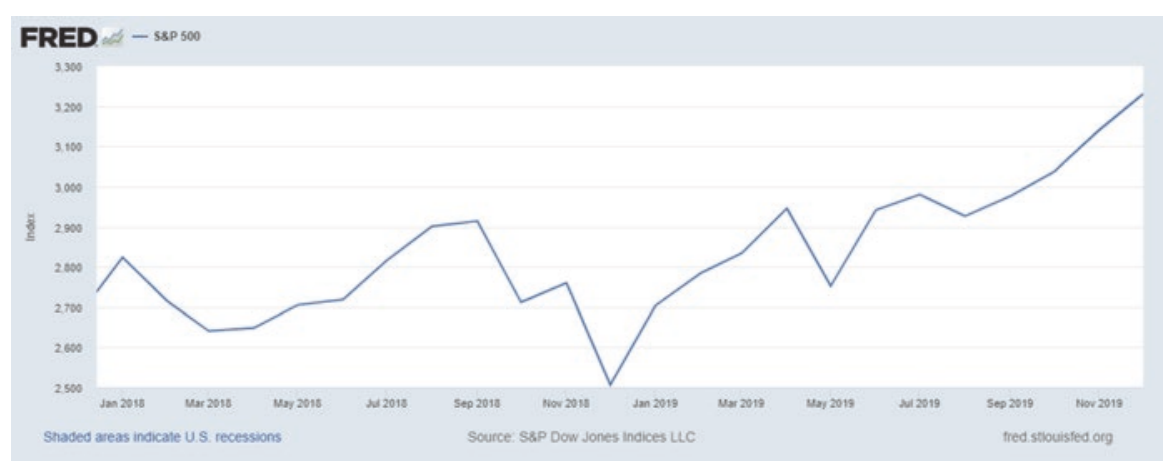

Exhibit 3.3 S\&P 500 stock market index longer-term movements (2018-2019)

financial market participants had thought that a Federal Funds rate of $2.5 \%$ was sufficient to maintain strong economic growth while keeping inflation in check. Exhibit 3.1 shows the path of this key interest rate during August 2015-December 2019.

Given the market's expectations in early October 2018, the Fed chairman's statements were a shock to most investors. They feared the Fed might be too aggressive in its contractionary monetary policy and could eventually push the economy into a recession. Accordingly, 10-year U.S. Treasury note yields initially jumped to $3.21 \%$ after the announcement before falling to $2.69 \%$ by the end of 2018 , while stocks sank $14 \%$ throughout the fourth quarter. Fears of a recession prompted these sharp reactions and created a great deal of price volatility in bond and stock markets. Exhibit 3.2 shows the path of Treasury note yields during 2018-2019, and Exhibit 3.3 displays the S\&P 500 stock market index over this time period.

Exhibits 3.2 and 3.3 provide vivid illustrations of how financial markets interact with the macroeconomy in a way where each influences the other. This can be seen not only by the rapid declines in bond yields and stock prices in 2018 but also in the positive responses to the Fed's subsequent statements and actions in 2019 to first pause and then ultimately lower the Federal Funds rate. After initially spooking the financial markets in 2018, the Fed's actions sparked major rallies in both the stock and bond prices during 2019. ${ }^{3}$ Along the way, market participants were constantly assessing any new information about the Fed's tendencies, and the Fed itself closely monitored the market's reactions to its changes in monetary policy.

We can also "zoom in" to examine how the stock market reacted to the Fed chairman's comments by looking at the intraday prices surrounding the specific dates of these statements. Intraday price movements on October 3-5, 2018, for the S\&P 500 are presented below.

As one can see from Exhibit 3.4, there is a strong and swift reaction to Chairman Powell's surprise comments about the need for further interest rate increases. Notice

\footnotetext{
${ }^{3}$ Note that bond prices move inversely with interest rate changes, so the dramatic decline in the 10-year U.S. Treasury note yield from over 3.2\% in October 2018 to 1.5\% in August 2019 generated large capital gains for bond investors.
} 


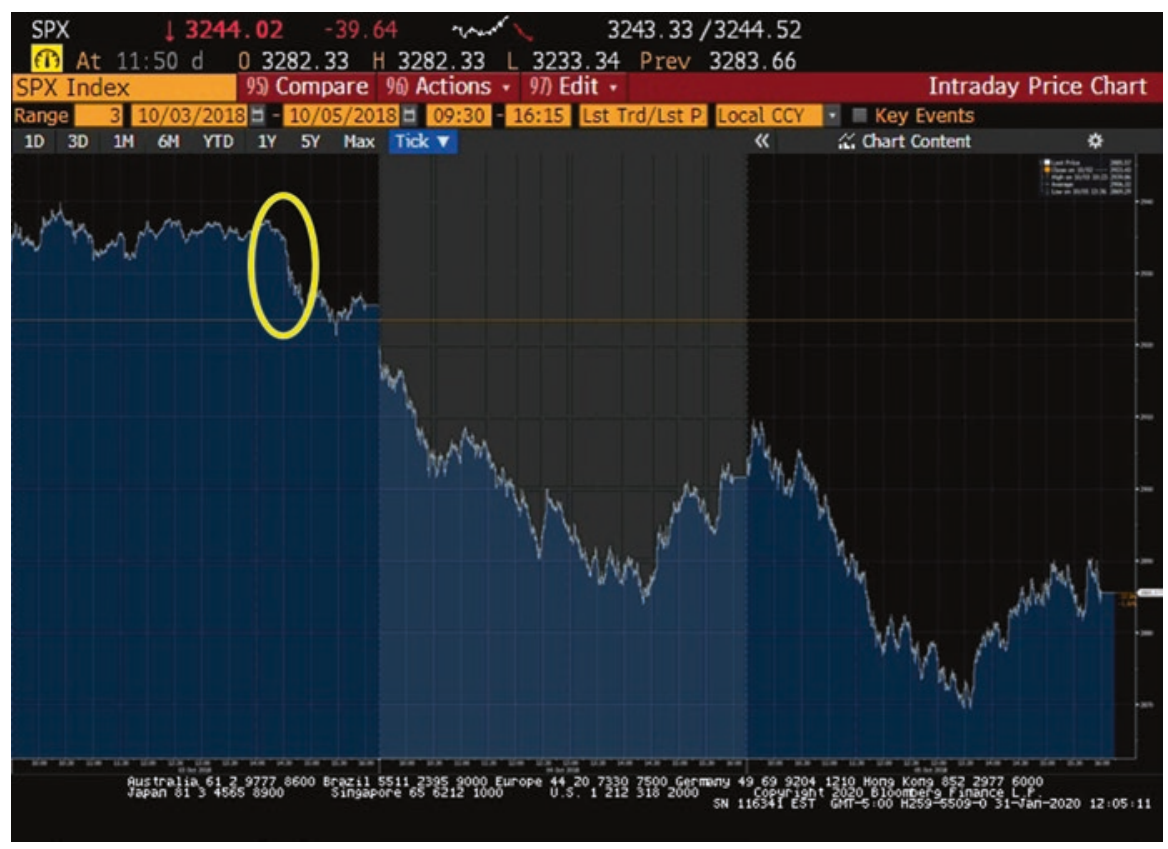

Exhibit 3.4 S\&P 500 stock market index intraday movements (October 3, 2018-October 5, 2018)

that the reaction began during the afternoon of October 3rd right after the chairman's comments were made public (highlighted in the graph by the oval). When markets are informationally efficient, we expect this type of quick reaction to unexpected news. As shown below in Exhibit 3.5 for a single day, the initial fall was immediate and steep (a $0.4 \%$ drop from the market's peak at 2:15 pm to the close at 4:00 pm on October 3); the market's sell-off continued during October 4-5 for a total decline of $1.8 \%$ from its pre-announcement peak as market participants fully processed the implications of possible continued interest rate hikes on the economy and financial markets. ${ }^{4}$ By zooming in further, we can see by the circle in Exhibit 3.5 that most of the initial reaction in the S\&P 500 occurred between 2:15 pm and $2: 55 \mathrm{pm}$. This type of pattern commonly occurs when the financial market's initial response is swift and strong, but as the earlier graph in Exhibit 3.4 shows, the trend in prices can continue for several days as the process of harmonizing divergent expectations through trading plays out between "bulls" and "bears."

In contrast to the stock market's behavior in October 2018 shown above, we can also consider another sharp and rapid reaction, but now in the opposite direction for the S\&P 500 index. As noted earlier, the market responded positively to Powell's more conciliatory comments related to putting potential future rate increases on

\footnotetext{
${ }^{4}$ If this decline over $2+$ days were annualized, the cumulative loss would be approximately $84 \%$ of an investor's original value after 1 year.
} 


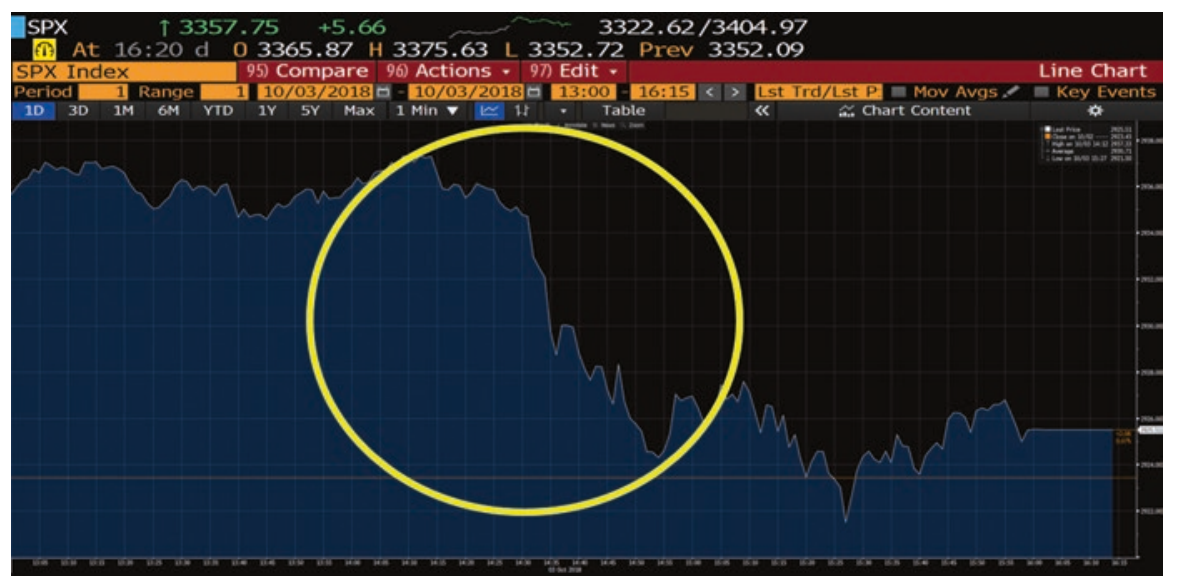

Exhibit 3.5 S\&P 500 stock market index intraday movements (October 3, 2018)

hold early in 2019. This reaction can be seen in Exhibit 3.6 by the intraday price patterns for this major stock index during January 3-4, 2019.

Exhibit 3.6 shows a large jump during the early morning on January 4, 2019 (see the first oval in the graph). The initial positive reaction at the market's 9:30 am open was due to a surprisingly robust nonfarm employment report released earlier that morning at 8:30 am which showed 312,000 jobs were created in the United States during December 2018. Once the stock market reopened at 9:30 am on January 4, the S\&P 500 stock index surged to 2475.90 (a $1.1 \%$ increase from the prior day's close of 2447.89). This large, discontinuous jump from the previous closing price is referred to as a "gap up" in the parlance of technical analysis (which is discussed in the final section of this chapter). This is a classic example of how financial markets respond quickly to unexpected positive news about the macroeconomy.

The stock market then jumped a second time later that morning between 10:00 am and 11:00 am because Chairman Powell stated that the Fed was contemplating putting future Federal Funds rate increases on hold. Like the pattern shown earlier in Exhibits 3.4 and 3.5, the chairman's public comments about monetary policy were unexpected, and thus, traders and investors responded quickly, as can be seen by the second oval shown in Exhibit 3.6. The net effect on stock prices was swift and sizable. The index then continued to trend up over the rest of the day and closed at 2531.94 for a total gain of $3.02 \%$ from the prior day's close. This represents a large gain because U.S. stock market indexes typically fluctuate less than $1 \%$ on a daily basis.

Exhibit 3.7 shows how differences in the liquidity of individual securities can affect the price discovery process around Chairman Powell's comments on January 4, 2019. To illustrate how two stocks can react in very different ways to the same news from the Fed chairman, Exhibit 3.7 shows the intraday price patterns from 9:30 am to 11:15 am on that day for a very liquid stock, Microsoft (a global software giant), and a fairly illiquid stock, Flushing Financial (a small commercial bank 


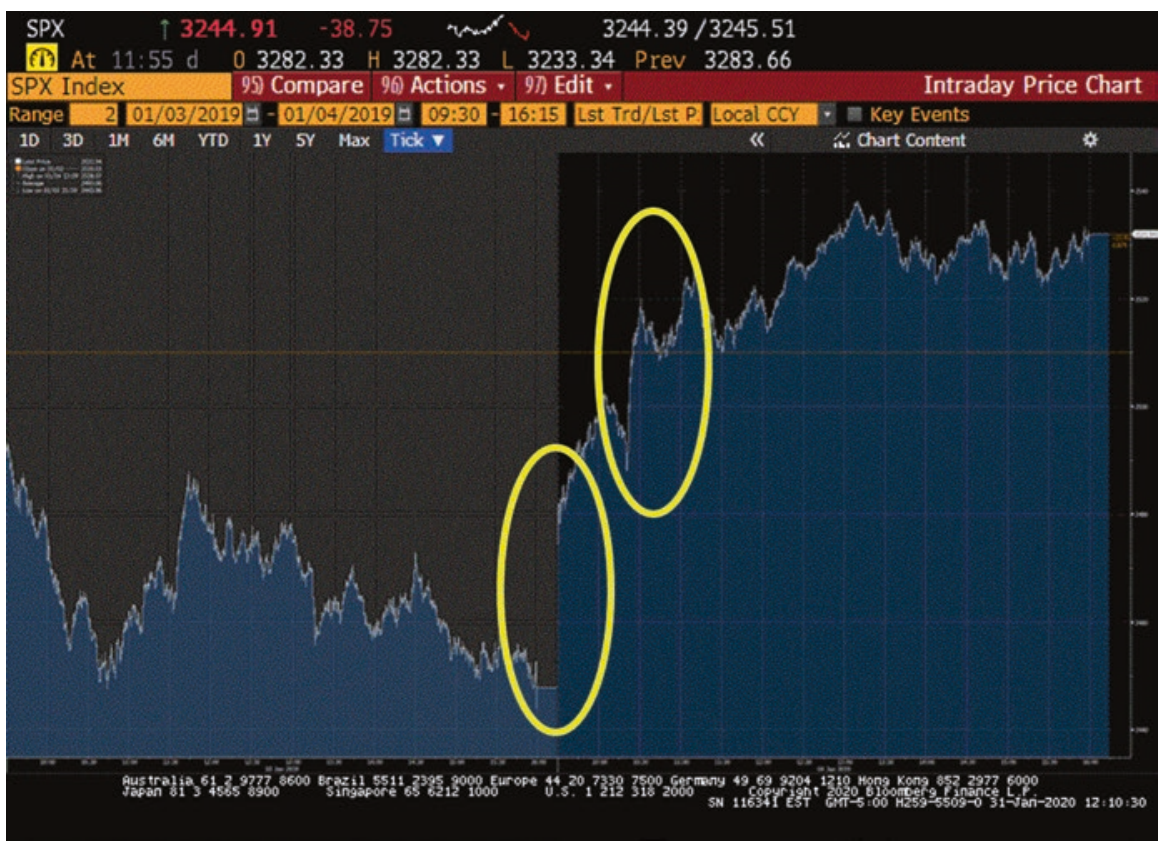

Exhibit 3.6 S\&P 500 Stock Market Index Intraday Movements (January 3, 2019-January 4, 2019)

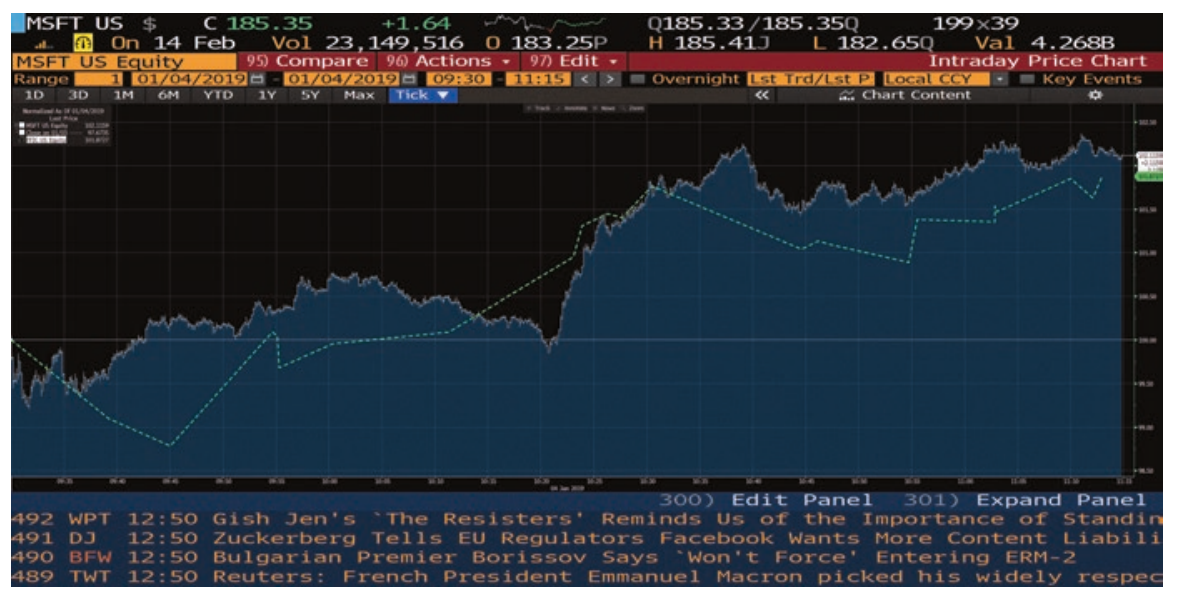

Exhibit 3.7 Large versus small cap stocks' intraday movements (January 4, 2019)

based in New York City). The white line traces the fluctuations for Microsoft stock, while the dashed line displays the movements in Flushing Financial. ${ }^{5}$ Notice that Microsoft's price pattern is much smoother because trades occur frequently and at

${ }^{5}$ Both stocks have been indexed to a starting baseline value of 100 to facilitate comparison. 
prices that are fairly close to prior prices. So despite the major news from the Fed that day, Microsoft's stock responds quickly and in a "fair and orderly" manner because many trades were being executed within every minute of trading.

In contrast, the dashed line of Flushing Financial moves in an abrupt, jagged way because its stock does not trade that frequently. This also leads the stock's price to lag behind movements in the S\&P 500 stock index and Microsoft. In fact, during the 9:30-11:15 am period on this day, Flushing Financial's stock traded only 25 times, while Microsoft traded 2,520 times! In addition, the total daily share trading volume was 44,061,000 for Microsoft and only 67,250 for Flushing Financial.

This represents a very large difference in trading activity, with Microsoft's stock exhibiting much greater liquidity, as buyers and sellers can easily trade at any time during the trading (e.g., 24 times per minute on average). In contrast, Flushing Financial's stock does not trade very often over this time period (once every 4.2 minutes), and thus, its price must move more sharply when it does eventually trade in order to "catch up" to news about the U.S. jobs report and the Fed chairman's comments. Thus, discovering the "correct" price for an illiquid stock like Flushing Financial is much more difficult because of the lack of frequent trades. Although this graph shows only two stocks, these differences in liquidity exist across the thousands of stocks that trade in the United States on any given day.

The trading mechanics and price discovery process described earlier in this chapter were the primary instruments needed to facilitate these interactions between the macroeconomy and financial markets. Thus, it is important to have well-functioning, liquid financial markets to make the signals between policymakers, investors, business executives, and consumers as clear as possible.

\subsection{Using the TraderEx Simulation to Understand Interactions Between Financial Markets and the Macroeconomy}

The TraderEx trading simulation system is an excellent way to demonstrate and "bring to life" the concepts described thus far in this book about liquidity and market structure. Specifically, this chapter focuses on the interactions between financial markets and the macroeconomy. TraderEx can be played among multiple players in a "network session" environment or in a "solitaire session" mode against the computer. It accommodates the three main types of markets (order-driven, quote-driven, and call auction). More details on how to operate the TraderEx system can be found in Chapter 5, Experiencing Market Dynamics with TraderEx: A Trading DecisionMaking Simulation. In this section here, we focus on how the concept of information shocks can be brought to life via the TraderEx system.

One can incorporate information shocks related to macroeconomic news into the simulation either by having the instructor provide brief, unexpected "news items" within the system for everyone to see or by simply announcing the information aloud to all players. A variant on this type of game play would be for the instructor to provide this macroeconomic news privately to only a select few participants in 
order to simulate "an informed trader" environment where some players have an information advantage over other participants. For example, one could first provide news privately about an impending positive U.S. employment report to the proprietary traders and then announce this news publicly to the rest of the players in the class later in the simulation. Similarly, news about a sudden change in the Federal Funds rate could be shared privately at first or announced publicly to everyone at the same time.

If the players are acting in an efficient way, then one would expect those with private information to place market orders to buy when the news is positive and to place market orders to sell when the news is negative. In addition, divergent expectations can lead some informed traders to buy, while other informed investors decide to sell. Either way, the informed players can quickly take advantage of their informational edge. Attentive buy-side traders that are uninformed could also adjust their limit orders based on a sudden surge in market orders by informed traders. For example, those uninformed traders with a buy mission might cancel their existing buy orders and enter new orders at higher bid prices if they fear that there are many market buy orders by informed traders that will quickly push prices upward. To increase the likelihood of getting their orders executed, these uninformed investors will want to raise their bids to be more in sync with the sudden jump in transaction prices caused by the informed traders' actions. Those uninformed investors with a sell mission might follow a similar approach by canceling their original orders and placing new sell orders at a higher limit price. The reverse would be true for these buy-side traders if the news was negative and many market sell orders by informed traders have flooded in (i.e., uninformed traders would cancel the original orders and replace them with lower bid and ask prices to increase their chances of getting their orders filled). By carefully observing the trading activity, the uninformed participants can infer a great deal about the informed traders' private knowledge which can then lead to better price discovery and improved market efficiency.

After reviewing the TraderEx results, it is usually best to re-run the simulation with each player trying the role of a different type of trader (e.g., a market maker can become a buy-side trader or informed trader in the second round of game play and so on). In this way, one can get a sense of how different objectives can affect the way a trader reacts to macroeconomic news and how traders will handle their orders to achieve specific goals.

\subsection{Making the Trade: Combining Macroeconomics with Fundamental Analysis and Technical Analysis}

The final point we consider in this chapter is how an investor can use the concepts we have presented to make effective investments in a real-world financial market such as the New York Stock Exchange or Nasdaq. Economists and other market participants also need to understand an investor's perspective in order to anticipate how economic policies and conditions can impact the liquidity of financial markets and how these markets can influence interest rates and the macroeconomy. 
Since macroeconomic conditions can appreciably affect the future cash flows for a stock, investors must be attuned to the trends in key economic indicators. For example, investors typically monitor the growth in real gross domestic product (GDP), employment and wages, business investment, personal consumption, corporate profits, as well as changes in interest rates, inflation, and productivity, to name a few of the economy's major variables. In addition, as demonstrated in a prior section, one must understand and follow changes in a government's monetary and fiscal policies because they can have profound effects on the economy in general and on financial markets in particular. An investor interested, for example, in buying the stock of a hypothetical company called $\mathrm{ABC}$ would like to see that the economy is operating in a "virtuous cycle" where employment and wage growth is strong because this will encourage increased consumption by consumers which, in turn, translates into increased sales and profits for corporations. The greater prosperity of consumers and businesses will then typically spur increased investment by these businesses which can lead them to hire more employees and pay them higher wages. This sets off another stage of greater consumption by consumers and further economic growth. In the ideal case, this virtuous cycle continues without triggering increases in inflation and interest rates. If inflation and interest rates start to rise, then the Fed and other policymakers must decide whether contractionary monetary and fiscal policy is called for to cool down the economy before it "overheats."

Conversely, a "vicious" economic cycle can set in if consumers suddenly stop spending as much as in the past, possibly due to concerns about the future political climate and economic conditions. This can lead to lower sales and corporate profits, less business investment, and ultimately employee layoffs, which can then reinforce consumers' concerns, causing them to spend even less, which leads to a further decline in corporate profits. In this case, the economy becomes mired in a negative cycle where conditions continue to deteriorate, and the economy falls into a recession. As that point approaches, the Fed and other government policymakers must decide whether expansionary monetary and fiscal policies are needed to stimulate the economy and break this negative cycle.

The above discussion reveals the importance of first understanding the country's macroeconomic conditions to decide how much one should be invested in the stock market at the current time. If economic conditions are good, then investing more in the stock market is a viable option, and so the next step is to evaluate various sectors of the economy to see which might perform the best in the near future. ${ }^{6}$ For example, auto manufacturers tend to do well as an economy emerges from a recession, while technology stocks typically perform best in the middle of an economic expansion. In contrast, consumer product companies such as food producers and utility companies tend to outperform at the end of an economic expansion and the beginning of a recession. This "rotation" between different industries, or economic sectors, requires the investor to be aware of current trends in the business cycle.

\footnotetext{
${ }^{6}$ The approach we focus on here is commonly referred to as a "top down" investment style. In contrast, some investors prefer to use a "bottom-up" approach where the prospects of individual companies are first analyzed, and the macroeconomic conditions are of secondary importance.
} 
Having identified current economic conditions and which sectors are likely to perform well, an investor can then perform "fundamental analysis" to identify which stock(s) to buy. This analysis typically requires that the investor study the firm's trends in growth, profitability, and risk-taking. Ideally, an investor should select a firm that has strong growth, consistently high profitability, and a relatively low risk business model. A good fundamental analysis would also entail estimating a firm's fundamental or "intrinsic value" by forecasting future cash flows and discounting these flows using a cost of capital that is commensurate with the firm's riskiness. In this way, an investor can determine if his/her estimate of the firm's fundamental value is greater than the firm's current price observed in the stock market. If so, then the stock is trading at a cheap price relative to its intrinsic value and should be considered for purchase. For example, if an investor thinks ABC is worth $\$ 30$ per share and the current stock price is only $\$ 25$, then the investor can make a $\$ 5$ dollar profit if other market participants eventually realize that the firm should be valued at this higher price.

An investor might also want to consider one final aspect before placing a limit or market order to buy ABC stock at $\$ 25$ per share. That is, after identifying a potentially profitable investment in $\mathrm{ABC}$, some investors will also perform "technical analysis" to see if this is the right time to buy the stock. For example, if ABC's stock price has been trending down over the past 3 months, an investor might want to use technical analysis to determine whether this short-term trend will continue. If this trend does continue, then the investor is actually better off to wait for the price to decrease further in the near future so that he/she can buy ABC for even lower than $\$ 25$ per share (in which case, the profit will be greater when the price rebounds and ultimately climbs to the investor's projected price of \$30).

However, for past price patterns to be useful, one needs to know whether financial markets are informationally efficient and thus conform to the "efficient market hypothesis" (EMH) discussed in the Finance chapter. In our context, if information shocks cannot be predicted and financial markets are perfectly efficient, then past prices are not of any help either in the short or long term. In such a market, stock price changes are uncorrelated, and price moves resemble a "random walk" pattern.

Have the random walk and the EMH been validated? From our perspective on trading, the most relevant tests of the EMH are based on very short period, intraday data; and the tests have shown that intraday correlation patterns do indeed exist, thus rejecting the EMH - at least over short time intervals. On any given day, both positive and negative intraday correlation patterns exist in complex combinations. The patterns also continuously evolve, and so exploiting them with technical analysis or any other tools is far from an easy task. Nevertheless, astute traders recognize and deal with these realities when implementing their investment decisions.

Technical analysis uses the recent history of stock prices and trading volume to predict future stock values and, in this case, might identify a short-term price "bottom" of, say, \$22 per share for ABC's stock. So an investor would use this shortterm forecast to wait until ABC's price dropped to $\$ 22$, with a goal of placing a limit buy order at this price point. If the investor is correct in both the technical and fundamental analyses, then the purchase order will execute at $\$ 22$, and the gain from 
the trade will be greater at $\$ 8$ per share $(\$ 30$ - \$22) rather than the $\$ 5$ per share profit based solely on fundamental analysis.

Although this is not the place where we could possibly do justice to all of the details and nuances of technical analysis, one example of this technique is the use of a simple "cross-over" strategy where a price bottom can be identified when the current price rises above a moving average of past prices (e.g., the price rises to $\$ 22$ when the 65-day moving average is $\$ 21){ }^{7}$ This cross-over suggests that prices will now continue on an upswing because the new price of $\$ 22$ has broken the old pattern of lower prices at $\$ 21$. Clearly, there are many different types of technical analysis patterns (typically referred to as "studies"), and it can take several years for a person to become an expert in all of them. In response to this proliferation of technical studies, computerized trading algorithms have also been created to help automate and sharpen this type of analysis. This complexity of trading patterns is consistent with our view that price discovery is a difficult, protracted process that involves runs and reversals that might be detected by technical analysis and dealt with via sophisticated trading algorithms.

\subsection{Wrapping Up: How Information Shocks Affect Financial Markets and the Economy}

Market participants can benefit greatly from knowing how the macroeconomy and financial markets interact with each other. For example, a deeper understanding of the prominent role of macroeconomic-related information shocks could help one identify via fundamental analysis which industries (and what firms within those sectors) will perform well in the future. In addition, the specific timing and placement of trades could be enhanced if effective technical analysis techniques are employed. By employing the concepts and analytical tools described in this chapter, financial assets can be assessed more accurately, and the financial markets' signals to the macroeconomy will be clearer, thus benefiting society.

It should also be noted that the 2020 COVID-19 pandemic offers another vivid illustration of how the economy and stock market can react to an information shock. In this case, the information shock was "exogenous" to the macroeconomy and financial markets (i.e., it originated outside of the economy due to the rapid global spread of the novel coronavirus in 2019-2020). As economies and societies around the world were "locked down" to halt the virus's spread, the economic and financial effects were immediate and severe. In the United States, the unemployment rate went from record lows to historic highs within a matter of months during the first half of 2020. Due to this health crisis-induced shock to the economy, investors quickly sold stocks and sought the safety of U.S. Treasury securities, both of

\footnotetext{
${ }^{7}$ Conversely, a cross-over strategy to sell a stock would occur when the current price falls below a moving average of past prices. Please note that in this section, we neither support nor deny the validity of technical analysis, but only note that it is being used today by many traders. Our intention here is to give you a quick sense of what is involved with this widely used technique.
} 
which pushed stock prices and Treasury yields down. In turn, governments quickly intervened with monetary and fiscal stimulus to soften the powerful blow to the economy and to provide time for scientists to come up with therapeutics and ultimately a vaccine. As the drama unfolded, the stock market whipsawed between gut-wrenching plunges and sharp upswings, while intraday volatility surged to record highs in the United States and elsewhere. The driving force for these sudden movements was the nature of the information about the growing pandemic. This virus-related news was often complex, conflicting, and, in many cases, quite unreliable. Consequently, investor expectations were extremely divergent, and this no doubt added to the substantial surge in short-term price volatility. The violent market fluctuations during the first half of 2020 are another dramatic example of how financial markets and the economy interact with each other in the face of unexpected news.

Open Access This chapter is licensed under the terms of the Creative Commons Attribution 4.0 International License (http://creativecommons.org/licenses/by/4.0/), which permits use, sharing, adaptation, distribution and reproduction in any medium or format, as long as you give appropriate credit to the original author(s) and the source, provide a link to the Creative Commons license and indicate if changes were made.

The images or other third party material in this chapter are included in the chapter's Creative Commons license, unless indicated otherwise in a credit line to the material. If material is not included in the chapter's Creative Commons license and your intended use is not permitted by statutory regulation or exceeds the permitted use, you will need to obtain permission directly from the copyright holder.

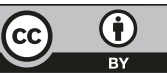

